\title{
Educação Financeira na Escola Básica: um experimento com Modelagem Matemática
}

\section{Financial Education in the Basic School: one experiment with Mathematical Modeling}

Rodrigo Sychocki da Silva ${ }^{1}$, Morgana Aline Reinheimer ${ }^{1}$

\section{RESUMO}

Este artigo apresenta um experimento de ensino realizado no Ensino Fundamental, que fez uso da Modelagem Matemática no desenvolvimento de conceitos relativos à Educação Financeira, o qual visava oportunizar a compreensão de ideias relativas à educação financeira na formação dos jovens. A proposta foi desenvolvida com a meta de alcançar os seguintes objetivos: mostrar a importância do desenvolvimento da educação financeira, tornar o indivíduo consciente para todas as decisões que envolvam dinheiro, estimular 0 desenvolvimento de ações cooperativas, refletir sobre a importância de pesquisar e comparar preços e por consequência desenvolver o senso crítico. Como aporte metodológico optou-se pela utilização de uma metodologia qualitativa a fim de refletir sobre as descobertas e aprendizagens que ocorreram durante 0 experimento. $\mathrm{O}$ grupo de estudantes que participou foi colocado diante de impasses e desafios que visavam 0 uso racional dos recursos financeiros. A título de conclusões da pesquisa observou-se que as reflexões sobre os conceitos estudados e as ações desenvolvidas pelos estudantes, de forma individual e coletiva, visavam alcançar o êxito do grupo, ao invés do pessoal.

Palavras-chave: Educação crítica; Educação Financeira; Ensino Fundamental; Modelagem Matemática.

\begin{abstract}
This article presents a teaching experiment conducted in elementary school, which made use of mathematical modeling in the development of concepts related to financial education, which aimed to provide an opportunity to understand ideas related to financial education in youth education. The proposal was developed with the goal of achieving the following objectives: show the importance of developing financial education, make the individual aware of all decisions involving money, stimulate the development of cooperative actions, reflect on the importance of researching and comparing prices. and consequently develop critical sense. As a methodological contribution, we chose to use a qualitative methodology to reflect on the discoveries and learning that occurred during the experiment. The group of students who participated was faced with impasses and challenges aimed at the rational use of financial resources. As conclusions of the research it was observed that the reflections on the concepts studied and the actions developed by the students, individually and collectively, aimed to achieve the success of the group, rather than the personal.
\end{abstract}

Keywords: Critical Education; Financial Education; Elementary School; Mathematical Modeling.

\footnotetext{
${ }^{1}$ UFRGS - Universidade Federal do Rio Grande do Sul, Porto Alegre/RS - Brasil
} 


\section{INTRODUÇÃO: EXPLANANDO A PROBLEMÁTICA}

A educação financeira é nos dias de hoje componente curricular das escolas brasileiras e o tema vem ganhando espaço, pois segundo dados recentes o número de cidadãos endividados cresce progressivamente. De acordo com a Pesquisa Nacional de Inadimplência do Consumidor, realizada pela Confederação Nacional do Comércio de Bens, Serviços e Turismo (CNC²) em dezembro de 2017, o percentual das famílias com dívidas aumentou alcançando $56,2 \%$ das famílias.

A comunidade acadêmica (Hofmann e Moro (2012), Pelicioli (2011), Fernandes e Vilela (2019), Campos et. al. (2015), Silva (2019), Carrara (2017), Gomes (2015), entre outros) têm discutido sob a ótica de oportunizar desde cedo, no âmbito da educação básica, experimentações as quais os estudantes tenham acesso e às situações que envolvam construção de reflexões e consequentemente tomada de decisão.

Sob esta problemática, o presente trabalho tem como objetivo principal evidenciar a importância e inserção da temática de estudo da educação financeira já na escola básica. Aspira-se no presente texto apresentar e analisar atividades realizadas em 2018 no sexto ano do ensino fundamental e que possibilitaram aos educandos produzir reflexões sobre suas decisões no que tange a manutenção de sua própria vida financeira. Pretendeu-se estimular os educandos a refletir sobre questões emergentes tais como: Por que poupar? De onde vem o dinheiro? Qual a importância do planejar? A construção e execução das práticas de ensino foram norteadas pelo conceito de Modelagem Matemática apresentados por Bassanezi (2004), Biembengut e Hein (2007) e Skovsmose $(2000,2004)$. Os conceitos permitiram ao longo da pesquisa construir e tentar responder a seguinte pergunta: Como a Modelagem Matemática pode auxiliar na compreensão da importância da educação financeira na formação dos jovens?

A pesquisa contemplou o desafio de proporcionar aos estudantes uma visão positiva da educação financeira e de sua finalidade. A presente pesquisa em consonância com a visão de mundo e de conhecimento da pesquisadora e primeira autora do seguinte texto almejou os seguintes objetivos: mostrar a importância do desenvolvimento da educação financeira em todas as etapas da vida; tornar o indivíduo consciente para as decisões que envolvam dinheiro, ou seja, que ele esteja ciente das oportunidades e riscos de todas as ações que pode tomar; estimular o espírito cooperativo e refletir sobre a importância de pesquisar e comparar preços.

O presente texto está organizado da seguinte forma: a segunda seção apresenta a fundamentação teórica necessária para a análise e compreensão dos fatos observados no experimento de ensino; a terceira seção apresenta as características metodológicas, materiais e métodos utilizados do estudo. A quarta seção apresenta uma análise e reflexão sobre o experimento de ensino realizado no ensino fundamental e que envolveu a temática da educação financeira. Por fim, a quinta seção explana considerações sobre o experimento realizado e lança luz sobre o potencial da temática já ser inserida e discutida desde a escola básica.

\footnotetext{
2 Disponível em: http://cnc.org.br/imprensa/economia/cnc-percentual-de-familias-endividadas-aumenta-emfevereiro-apos-quatro-quedas-con (Acesso em fevereiro de 2019)
} 


\section{ESCRITOS TEÓRICOS SOBRE MODELAGEM MATEMÁTICA}

Nesta seção pretendemos apresentar as definições de Modelagem Matemática (MM) que foram utilizadas para o desenvolvimento da pesquisa. Serão considerados conceitos trazidos essencialmente por Bassanezi (2004), Biembengut e Hein (2007), D'Ambrosio (1986) e Skovsmose (2000, 2004).

A perspectiva apresentada por Bassanezi (2004, p.24) apresenta que a Modelagem Matemática possa ser entendida como: "[...] um processo dinâmico utilizado para a obtenção e validação de modelos matemáticos. É uma forma de abstração e generalização com a finalidade de previsão e tendências". Segundo o autor, modelo matemático "é um conjunto de símbolo é relações matemáticas que representam de alguma forma o objeto estudado" (BASSANEZI, 2004, p.20). Para este autor a modelagem deve seguir uma sequência de etapas: experimentação, abstração, resolução, validação e modificação.

Bassanezi (2004, p.17) manifesta que "é necessário buscar estratégias alternativas de ensino e aprendizagem que facilitem sua compreensão e utilização". Afirma ainda que a MM é "um processo que alia teoria e prática, motiva seu usuário na procura do entendimento da realidade que o cerca e na busca de meios de agir sobre ela e transformá-la" (BASSANEZI, 2004, p.17).

Biembengut e Hein (2007), outros autores que embasam está seção, afirmam que Modelagem Matemática é a interação entre matemática, situação real e modelo. Segundo Biembengut e Hein (2007, p.15) "a interação que permite representar uma situação "real" com ferramenta matemática envolve uma série de procedimentos". Os autores também destacam que "[...] modelação matemática norteia-se por desenvolver o conteúdo programático a partir de um tema ou modelo matemático e orientar o aluno na realização de seu próprio modelo-modelagem" (BIEMBENGUT; HEIN, 2007, p. 18).

D'Ambrosio (1986) trata a Modelagem Matemática como uma forma de interação do conteúdo de sala de aula com questões reais. De acordo com o autor a modelagem é um processo rico para encarar situações reais e culmina com a solução efetiva do problema que, de modo geral, não é matemático e não uma simples resolução formal de um problema artificial. O desenvolvimento da capacidade de interpretar e agir numa situação social e política estruturada pela Matemática está relacionado com uma dimensão do conhecimento chamada por Skovsmose (1990) de conhecimento reflexivo. Para o autor, este conhecimento, é utilizado como uma lente a ampliar e refinar a visão tem importante papel no desenvolvimento da compreensão que ajuda a clarear a visão de mundo, possibilitando ao indivíduo "enxergar-se" em seu contexto social.

Segundo Skovsmose (2000) as práticas de aula as quais os professores podem propiciar aos educandos, contrapondo os diferentes objetivos de uma aula baseada em exercícios daquela voltada para cenários de investigação. A combinação entre prática e referência (pura, semi-realidade e realidade) é denominada pelo autor de "ambientes de aprendizagem" (SKOVSMOSE, 2000, p.8). O autor explica que o ambiente de aprendizagem pode estar articulado nessa linha do paradigma do exercício ou dos "cenários para investigação" (SKOVSMOSE, 2000, p.14). Segundo o autor, um cenário para investigação é aquele que convida os alunos a se questionarem e serem os agentes que obtêm as explicações. $O$ convite é considerado aceito a partir do momento que o aluno se permite participar da proposta de atividade. Nesse ambiente, os alunos são os responsáveis pelo processo, o que se distingue de uma prática voltada ao paradigma do exercício.

O movimento entre os diferentes ambientes de aprendizagem é fundamental. O aluno deve perceber que os exercícios aplicados têm outras aplicações e atribuir sentido a elas, buscando assim outras fontes de 
informação que lhe possibilitam chegar a outras conclusões e até mesmo a outras interrogações. Segundo Skovsmose (2000, p. 14), "a educação matemática deve mover-se entre os diferentes ambientes [...] não considero a ideia de abandonar por completo os exercícios da educação matemática". A partir disso, nas palavras de Skovsmose (2004), ressalta-se que o conhecimento reflexivo seja aquele cujo foco está voltado para as funções e aplicações da matemática na sociedade, as quais orientam e conduzem os sujeitos de como agir diante de uma situação estruturada pela matemática.

\section{ESCRITO LEGISLATÓRIO SOBRE EDUCAÇÃO FINANCEIRA}

O documento de alcance nacional, que se denomina Base Nacional Comum Curricular (BNCC), traz em seu conteúdo orientações para o ensino da educação financeira:

Outro aspecto a ser considerado nessa unidade temática é o estudo de conceitos básicos de economia e finanças, visando à educação financeira dos alunos. [...] favorecendo um estudo interdisciplinar envolvendo as dimensões culturais, sociais, políticas e psicológicas, além da econômica, sobre as questões do consumo, trabalho e dinheiro. É possível, por exemplo, desenvolver um projeto com a História, visando ao estudo do dinheiro [...] (BRASIL, 2018, p. 267).

$\mathrm{Na}$ área legislativa a aprovação da Estratégia Nacional de Educação Financeira (ENEF³) foi um marco; onde se constata que no Brasil está lançando luz às discussões que envolvem a temática da educação financeira. Instituída pelo Decreto № 7.397 de 22 de dezembro de 2010, tem a finalidade de promover a educação financeira e previdenciária e contribuir para o fortalecimento da cidadania, a eficiência e solidez do sistema financeiro nacional e a tomada de decisões conscientes por parte dos consumidores.

Dentre outras, umas das estratégias do ENEF é o programa educação financeira nas escolas cujo objetivo é ajudar os alunos a enfrentarem os desafios cotidianos e a realizarem seus sonhos por meio do uso adequado de ferramentas financeiras, contribuindo assim para um futuro melhor não somente para si próprios como também para o país. Segundo menção no site PREVIC (Superintendência Nacional de Previdência Complementar), Organização para Cooperação e Desenvolvimento Econômico (OCDE) de 2005, educação financeira é:

O processo mediante o qual os indivíduos e as sociedades melhoram a sua compreensão em relação aos conceitos e produtos financeiros, de maneira que, com informação, formação e orientação, possam desenvolver os valores e as competências necessários para se tornarem mais conscientes das oportunidades e riscos neles envolvidos e, então, poderem fazer escolhas bem informadas, saber onde procurar ajuda e adotar outras ações que melhorem o seu bem-estar. Assim, podem contribuir de modo mais consistente para a formação de indivíduos e sociedades responsáveis, comprometidos com 0 futuro (Fonte: http://www.previc.gov.br/regulacao/educacao-revidenciaria/educacao-financeirae-previdenciaria/o-que-e-educacao-financeira (Acesso em Janeiro de 2019).

Portanto, a educação financeira proporciona inúmeras discussões sobre conceitos, oportunidades, investimentos, finanças, receitas, despesas, as quais oportunizam aos jovens desenvolver uma

\footnotetext{
${ }^{3}$ Disponível em: http://www.vidaedinheiro.gov.br/o-programa/ (Acesso em Janeiro de 2019)
} 
reflexão sobre os riscos de atitudes financeiras precipitadas, bem como, das vantagens de atitudes financeiras acertadas.

\section{METODOLOGIA, MATERIAIS E MÉTODOS USADOS NA PESQUISA}

A partir do fato de que o presente experimento ocorreu na sala de aula de uma escola durante um período de cinco meses, nossa construção teórico-metodológica converge para o pensamento de Bicudo (2013) que afirma:

O mundo real é o mundo percebido. Mas não é um mundo subjetivo, nem relativo ao sujeito. É uma realidade concreta, porque estruturada na rede dos significados construídos histórico e socialmente. Rede que se expande, que se transforma conforme a perspectiva pela qual é olhada. Olhada, porém, sempre de dentro da própria rede que, em última análise, é o mundo real vivido, dado como um círculo existencial hermenêutico onde tudo o que se quer é que ele faça sentido. Essa é a investigação primeira: o sentido que o mundo faz para cada um de nós e para todos ao mesmo tempo, pois são inseparáveis e totalizantes. (BICUDO, 2013, p. 124)

Portanto, a partir do pensamento exposto anteriormente, convergimos para uma escolha teóricometodológica que fosse de natureza qualitativa, segundo as ideias de Bogdan e Biklen (1994) citado por Borba e Araújo (2013). De acordo com os autores, a pesquisa qualitativa tem as seguintes características:

1. Na investigação qualitativa a fonte direta de dados é o ambiente natural, constituindo o investigador o instrumento principal;

2. A investigação qualitativa é descritiva;

3. Os investigadores qualitativos interessam-se mais pelo processo do que simplesmente pelos resultados ou produtos;

4. Os investigadores qualitativos tendem a analisar os seus dados de forma indutiva;

5. O significado é de importância vital na abordagem qualitativa. (BOGDAN e BIKLEN, 1994, apudBORBA e ARAÚJO, 2013, p.25).

Pelo fato dos estudantes que participaram da pesquisa terem desenvolvido ações a partir de suas tomadas de decisões entendeu-se que a pesquisa qualitativa pudesse servir como aporte para as observações e reflexões por parte da autora. Procurou-se de acordo com as características citadas anteriormente compreender quais significados, a partir das discussões sobre a temática da educação financeira, estavam sendo construídos pelos estudantes participantes.

A pesquisa foi desenvolvida com estudantes do sexto ano do Colégio XXX do município de XXX no estado do Rio Grande do Sul, que no ano de 2018 tinha 110 alunos entre Educação Infantil e Ensino Fundamental 2. A pesquisa teve duração de cinco meses, sendo que nos dois primeiros houve uma explanação dos conceitos da educação financeira e nos subsequentes o desenvolvimento dos cálculos, da viabilidade e a manutenção do projeto. Cabe mencionar que apesar do projeto ter ocorrido durante cinco meses, as aulas foram ministradas quinzenalmente durante aproximadamente uma hora cada.

Foram explanados os seguintes conceitos inerentes à temática da Educação Financeira: despesas, receitas, gastos supérfluos, a importância do planejar e do poupar. No primeiro encontro os alunos foram convidados a realizarem a leitura do texto "O que é despesa e o que é receita" ${ }^{\prime 4}$. Posteriormente cada aluno recebeu

\footnotetext{
${ }^{4}$ Disponível em: http://www.caixa.gov.br/educacao-financeira/aulas/despesas-e receita/Paginas/default.aspx (Acesso em Janeiro de 2019)
} 
um papel com uma descrição que envolvia uma despesa ou uma receita e deveria colocá-lo em uma das duas caixas identificadas com: DESPESA/RECEITA. Os alunos foram convidados a pesquisar junto aos seus familiares se em algum momento houve algo que desejassem muito e não puderam comprar em determinado momento.

No segundo encontro se explanou sobre os diferentes produtos que os familiares gostariam de obter e discutimos sobre os "4P's do Marketing": preço, praça, produto e promoção. Depois disso, os alunos foram orientados a pesquisar preços de diferentes produtos, os quais deveriam ser levados no próximo encontro.

$\mathrm{Na}$ terceira aula os alunos foram ao laboratório de informática pesquisar sobre a origem do dinheiro. Uma das alunas encontrou um texto interessante sobre o tema no site da casa da moeda do Brasil. Este texto foi reproduzido, realizamos a leitura do mesmo, debatemos e na quarta aula os alunos trouxeram vários tipos de cédulas (de outros países, antigas e com histórias particulares) para que pudéssemos observar e falar sobre seus países de origem e; compartilhar sobre as histórias dos familiares e a relação que eles tinham com as cédulas, tais como método de aquisição e motivos pelos quais as mesmas foram armazenadas.

Figura 1: Moedas trazidas por uma das alunas.

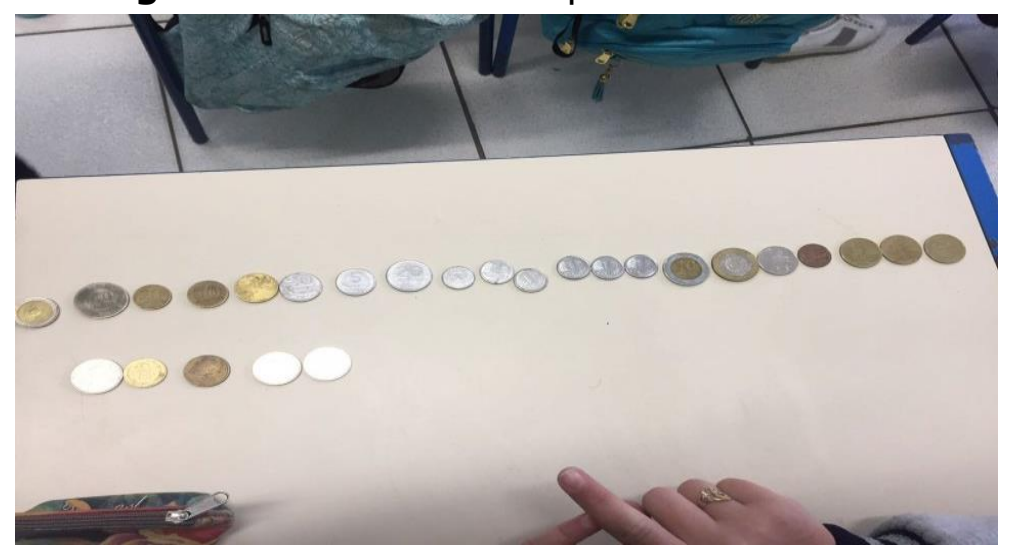

Fonte: Arquivo pessoal.

Nas próximas etapas os discentes começaram a refletir como os conhecimentos construídos poderiam auxiliá-los na obtenção de sucesso em um novo projeto que em consenso foi denominado de "LA CAIXA DA MOEDA". O principal objetivo foi entender a importância da aplicação dos conceitos da educação financeira utilizando a modelagem matemática e criando assim estratégias que possibilitassem a realização de alguma programação diferenciada no final de 2018. A professora proporcionou momentos de diálogo para que as ideias surgissem e as decisões coletivas fossem tomadas. Essas ações corroboram com Skovsmose (2004, p.18), que afirma:

Se queremos desenvolver uma atitude democrática por meio da educação, a educação como relação social não deve conter aspectos fundamentalmente nãodemocráticos. É inaceitável que o professor (apenas) tenha o papel decisivo e prescritivo. Em vez disso, o processo educacional deve ser entendido como um diálogo.

Em cada encontro um dos alunos passava com a caixa aos demais para que pudessem ser depositados os valores possíveis por cada um. Com o passar das aulas a professora convidou os alunos a criarem ações que maximizassem a arrecadação, facilitassem o controle do dinheiro e analisassem os custos. Situação semelhante é ilustrada em Biembengut e Hein (1990), em que os alunos investigaram qual era o custo para 
se construir uma casa. Para isto, eles listaram os materiais necessários, coletaram os preços, efetuaram cálculos e organizaram os resultados, sem construírem um modelo matemático propriamente dito.

Posteriormente, os estudantes envolvidos na presente pesquisa foram incumbidos de criar planilhas que facilitasse o controle financeiro. Alguns alunos trouxeram sugestões com preços acessíveis de programação, criaram formulários de controle utilizando o software Excel e realizaram brechós online e reais. Após os meses de execução do projeto definiu-se coletivamente que a meta seria arrecadar dinheiro para que os participantes pudessem fazer uma refeição numa pizzaria da cidade.

Figura2: Dinheiro arrecadado em cinco meses do projeto.

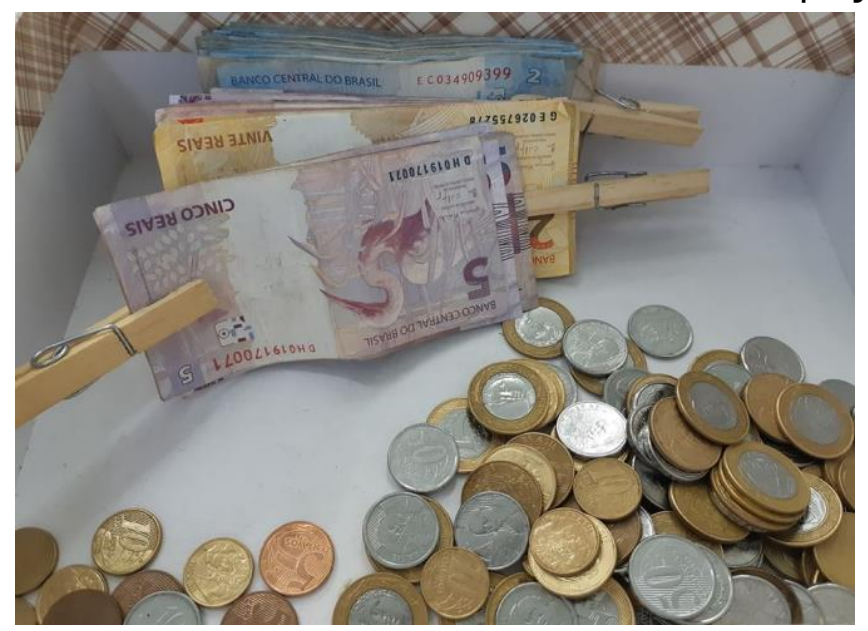

Fonte: Arquivo pessoal.

A arrecadação, conforme mostrada na figura 2, após cinco meses de execução do projeto foi tal que $100 \%$ dos valores investidos na realização do jantar foram provenientes das ações realizadas pelos estudantes.

\section{REFLEXÕES PÓS-EXPERIMENTO}

A utilização da Modelagem Matemática permitiu que os alunos refletissem sobre como suas ações poderiam modificar/melhorar as situações por eles vivenciadas no seu cotidiano. O marco inicial foi dado quando a professora, após explicar alguns conceitos relativos ao assunto, solicitou que os alunos identificassem algum problema que a turma desejasse investigar. Houve várias hipóteses, mas após discussões, todos consideram importante proporcionar algum momento no final do ano que todos pudessem participar, sem custo algum aos participantes, demonstrando uma preocupação social com relação ao grupo. Essas ações convergem para o conceito de formulação do problema trazido por Biembengut e Hein (2007, p. 14), que ressaltam:

É especialmente importante: classificar as informações (relevantes e não relevantes), identificando fatos envolvidos; decidir quais os fatos a serem perseguidos levantando hipóteses; selecionar símbolos apropriados para essas variáveis; e descrever essa relação com termos matemáticos.

A formulação do problema, assim como, o movimento entre os diferentes ambientes de aprendizagem conforme trazido por Skovsmose (2000) foi fundamental. O aluno pode perceber que os exercícios executados têm outras aplicações e atribuir sentido a elas, buscando assim outras fontes de informação que lhe possibilitaram chegar a outras conclusões e até mesmo a outras interrogações. Em consonância com as ideias de Skovsmose (2000, p. 14), "a educação matemática deve mover-se entre os diferentes 
ambientes [...] não considero a ideia de abandonar por completo os exercícios da educação matemática", logo na presente proposta isso e refletiu na explanação por parte dos estudantes da temática a qual todos estavam envolvidos.

À medida que as ideias surgiram, a viabilidade fosse sendo explorada, os discentes foram colocados em grupos para que começassem a refletir sobre como cada grupo poderia contribuir com uma proposta de uma maneira mais significativa e a partir daí as ações foram sendo tomadas. A adesão feita por todos sugerindo e promovendo brechós presenciais, brechós online e planilhas que permitissem analisar 0 andamento das ações. As reflexões acerca da viabilidade e a escolha considerada melhor por eles para que todos os alunos da turma pudessem participar e usufruir de um momento de final de ano especial corrobora para o que na visão de Skovsmose (2001) é educação crítica (EC): "uma investigação de condições para a obtenção do conhecimento, uma identificação dos problemas sociais e sua avaliação, é uma reação às situações sociais problemáticas [...] para ser crítica, a educação deve reagir às contradições sociais" (SKOVSMOSE, 2001, p.101).

Entende-se que essas ações aqui explanadas e relatadas nesse artigo constituem um pequeno passo na direção da Educação Matemática Crítica. Almeja-se em 2019 realizar o projeto com todas as turmas de sexto ao nono ano da escola participante sob a ótica de uma nova interrogação: O que podemos fazer para melhorar nossa escola? O retorno positivo da comunidade, conforme mostrado na figura 3 demonstrou o quanto esse tipo de atividade se faz necessário e ressalta que o ensino através da reflexão e dos aportes da modelagem torna-se significativo para os alunos, os quais podem se tornar agentes transformadores do meio onde vivem.

Figura 3: Recorte do feedback da comunidade após compartilhar imagens nas redes sociais.

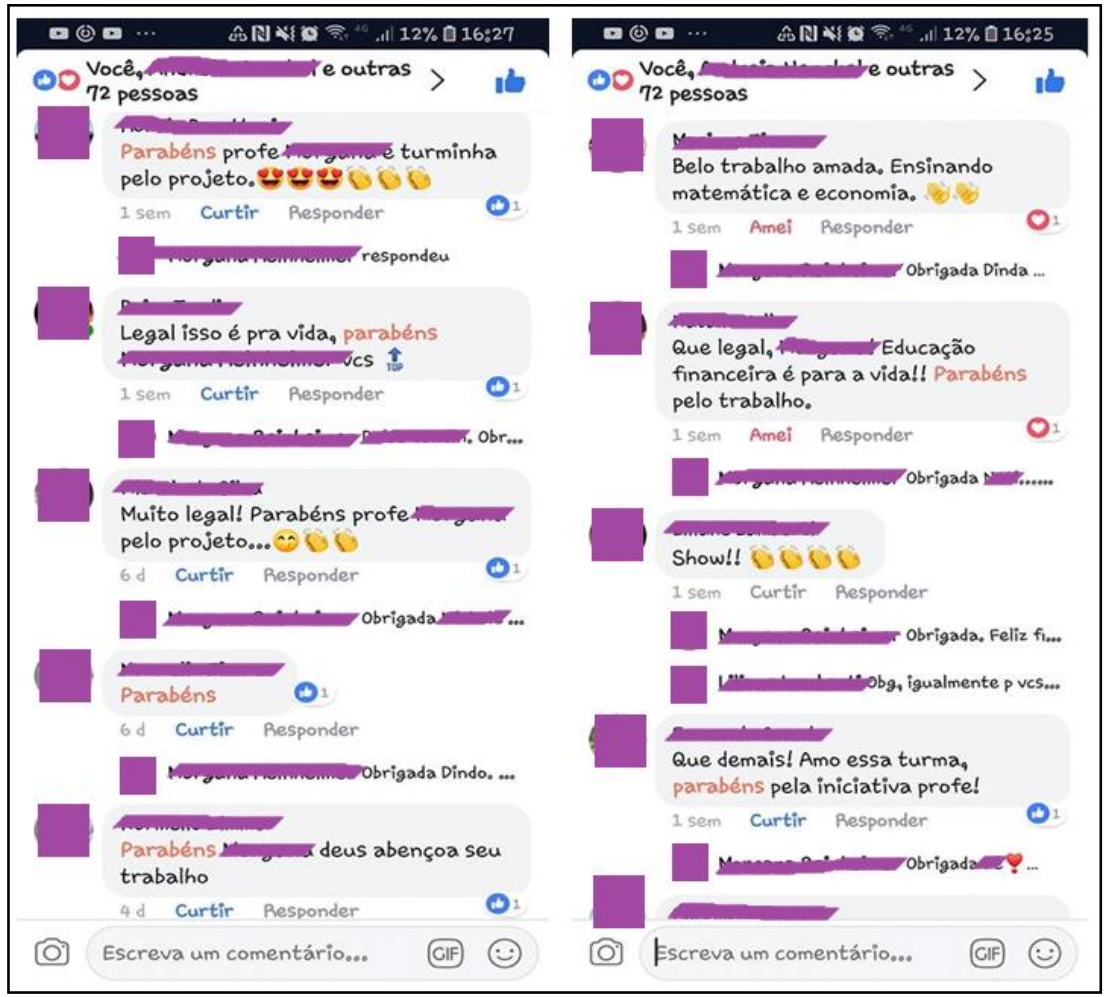

Fonte: Arquivo pessoal.

O feedback da comunidade nas redes sociais, entendido como positivo para as ações do projeto, enfatizam a importância da utilização da educação financeira no ensino básico e nos permitem inferir que o uso da Modelagem Matemática no ensino e reflexão das ideias que envolvam o uso de recursos financeiros pode 
oportunizar importantes e profícuas situações em sala de aula, as quais possibilitam uma aprendizagem que possa ser útil após o egresso da escola.

\section{CONSIDERAÇÕES FINAIS}

Conforme apresentado desde a introdução e reforçado pelos espaços de fundamentação teórica deste artigo a educação financeira é um tema contemporâneo e emergente na escola básica. Nosso entendimento converge para a posição de que a construção e execução de práticas que oportunizem momentos de discussão e reflexão sobre a temática sejam necessárias e deva ocorrer desde o ensino básico, tal como manifestaram também os estudos consultados no estado da arte.

Entende-se que os objetivos mencionados na introdução do texto e retomados aqui que foram: mostrar a importância do desenvolvimento da educação financeira em todas as etapas da vida; tornar o indivíduo consciente para as decisões que envolvam dinheiro; estimular o espírito cooperativo e refletir sobre a importância de pesquisar e comparar preços foram alcançados ao final do projeto. Entende-se que a utilização, por parte do professor, do aporte teórico da Modelagem Matemática para desenvolver com os estudantes uma educação crítica seja uma tarefa complexa e não trivial de ser feita. Porém, pode ser iniciada por meio da proposta de um trabalho coletivo, no qual o professor deve visualizar contribuições a médio e longo prazo para os estudantes participantes.

Percebeu-se como positivo o envolvimento dos participantes ao longo do projeto aqui explanado e agora compartilhado com a comunidade acadêmica por meio deste texto. Os estudantes desenvolveram estratégias, foram críticos, construíram e executaram planos de ações, individuais e coletivas, que oportunizaram o crescimento de todos. A leitura de mundo feita a partir do projeto pode nesse sentido contribuir para ações e tomadas de decisões que envolveram o uso racional do capital, seja de forma individual ou em família.

Por fim, não se considera a proposta aqui dissertada fechada ou concluída. A partir do feedback fornecido pela comunidade escolar entende-se e se faz o convite, para que mais professores de matemática se inspirem a levar para nossas salas de aula a discussão da temática relativa a educação financeira. A inserção pode ocorrer de forma gradual e progressiva, fazendo com que os participantes se tornem protagonistas das ações e construam significados próprios sobre o uso racional dos recursos financeiros nos dias de hoje.

\section{REFERÊNCIAS}

BASSANEZI, R. C. Ensino-aprendizagem com Modelagem Matemática. $2^{a}$ ed. São Paulo: Contexto, 2004.

BICUDO, M. A. V. Pesquisa qualitativa e pesquisa qualitativa segundo a abordagem fenomenológica. In: BORBA, M. C.; ARAÚJO, J. L. Pesquisa qualitativa em Educação Matemática. 5a edição. Belo Horizonte. Editora Autêntica. 2013.

BIEMBENGUT, M. S.; HEIN, N. Modelagem matemática no ensino. $4^{a}$ ed. São Paulo: Contexto, 2007.

BIEMBENGUT, M. S., HEIN, N.. Modelagem Matemática como Método de ensino aprendizagem de Matemática em cursos de $1^{\circ}$ e $2^{\circ}$ graus. Pós-Graduação em Educação Matemática. Universidade Estadual Paulista Júlio de Mesquita Filho, São Paulo. 1990. 
BOGDAN, R. C.; BIKLEN, S. K. Investigação qualitativa em educação. Tradução Maria João Alvarez, Sara Bahia dos Santos e Telmo Mourinho Baptista. Porto Editora. 1994.

BORBA, M.C.; ARAÚJO, J. L. Pesquisa qualitativa em Educação Matemática: notas introdutórias. In: BORBA, M. C.; ARAÚJO, J. L. Pesquisa qualitativa em Educação Matemática. 5a edição. Belo Horizonte. Editora Autêntica. 2013.

BRASIL. Ministério da Educação. Secretaria da Educação Básica. Base Nacional Comum Curricular. Brasília, DF, 2018. Disponível em: http://basenacionalcomum.mec.gov.br/\#/site/inicio. Acesso em dezembro de 2018.

CAMPOS, C. R.; TEIXEIRA, J.; COUTINHO, C. Q. S.. Reflexões sobre a educação financeira e suas interfaces com a educação matemática e a educação crítica. Educação Matemática Pesquisa: Revista do Programa de Estudos Pós-Graduados em Educação Matemática, [S.I.], v. 17, n. 3, p. 556-577, nov. 2015. ISSN 1983-3156. Disponível em: https://revistas.pucsp.br/emp/article/view/25671. Acesso em junho de 2019.

CARRARA, A. M. C.. Educação financeira: praticando o consumo consciente no ensino fundamental. 2017. 67 f. Dissertação (Mestrado em Ensino das Ciências na Educação Básica) Universidade do Grande Rio "Prof. José de Souza Herdy", Duque de Caxias, 2017. Disponível em http://tede.unigranrio.edu.br/handle/tede/285. Acesso em junho de 2019.

D'AMBROSIO, U. Da Realidade à Ação. Reflexões sobre Educação e Matemática. Ed. Universidade Estadual de Campinas, São Paulo. 1986.

FERNANDES, L. F. B.; VILELA, D. S.. Educação Financeira na Escola Básica Brasileira: um olhar sociológico. HIPÁTIA - Revista Brasileira de História, Educação e Matemática. v. 4 n. 1 (2019): Junho de 2019. Disponível em: https://ojs.ifsp.edu.br/index.php/hipatia/article/view/1098. Acesso em junho de 2019.

GOMES, R. F.. Desafios financeiros desenvolvendo competência em educação financeira de maneira lúdica. 2015. 56 f., il. Trabalho de Conclusão de Curso em Desenho Industrial. Universidade de Brasília, Brasília, 2015.2 Disponível em: http://www.bdm.unb.br/handle/10483/13091. Acesso em junho de 2019.

HOFMANN, R. M.; MORO, M. L. F. Educação matemática e educação financeira: perspectivas para a ENEF. Zetetike, v. 20, n. 2, p. 37-54, 8 maio 2013. Disponível em: https://periodicos.sbu.unicamp.br/ojs/index.php/zetetike/article/view/8646609. Acesso em junho de 2019.

PELICIOLI, A. F. A relevância da educação financeira na formação de jovens. Dissertação de Mestrado. Pontifícia Universidade Católica do Rio Grande do Sul. Programa de Pós-Graduação em Educação em Ciências e Matemática. 2011. Disponível em: http://tede2.pucrs.br/tede2/handle/tede/3405. Acesso em junho de 2019.

SILVA, L. M.. Educação Financeira Escolar: a noção de poupança no ensino fundamental. Dissertação (Mestrado Profissional). Universidade Federal de Juiz de Fora (MG). Instituto de Ciências Exatas. Programa de Pós-Graduação em Educação Matemática. 2019. Disponível em: https://repositorio.ufjf.br/jspui/bitstream/ufjf/10482/1/lucianamariadasilva.pdf. Acesso em junho de 2019.

SKOVSMOSE, O. Ud over matematikken. Systime Academic. 1990.

SKOVSMOSE, O. Cenários para investigação. Bolema - Boletim de Educação Matemática, 13(14), 66-91. 2000.

SKOVSMOSE, O. Educação Matemática Crítica - A Questão da Democracia. $2^{a}$ ed. Campinas: Papirus. 2004. 